\title{
Furosemide and spironolactone doses and hyponatremia in patients with heart failure
}

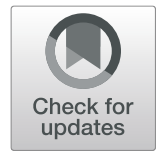

Ivan Velat ${ }^{1}$, Željko Bušić ${ }^{1}$, Marina Jurić Paić ${ }^{2}$ and Viktor Čulićc ${ }^{2, *^{*}}$

\begin{abstract}
Background: Hyponatremia, a marker of disease severity and prognosis, has been associated with various clinical factors and drug use, especially diuretics.

Methods: This observational prospective cohort study enrolled patients hospitalized at the University Hospital Center Split because of heart failure (HF). We investigated the association of clinical variables and cardiovascular drugs, including furosemide, hydrochlorothiazide, spironolactone, and their doses, with the presence of hyponatremia at admission.

Results: Of the 565 included patients, $32.4 \%$ were hyponatremic, $62.6 \%$ were males, and the mean age was $73.1 \pm$ 10.6 years. In the univariate analysis, hyponatremic patients were more often current smokers $(p=0.01)$, alcohol consumers $(p=0.01)$, receiving spironolactone $(p=0.004)$ or combination of furosemide and spironolactone $(p=$ 0.003). Patients who received 50 and $100 \mathrm{mg}$ of spironolactone, compared to those receiving $25 \mathrm{mg}(p<0.0001)$, as well as patients who received 250 to $500 \mathrm{mg}$ of furosemide compared to $\leq 240 \mathrm{mg}(p=0.001)$, were significantly more often hyponatremic. In the multivariate analysis, when diuretic doses were accounted for, furosemide doses of 250 to $500 \mathrm{mg}(p=0.009)$, spironolactone doses of 50 to $100 \mathrm{mg}(p=0.0003)$, increasing age $(p=0.03)$, diabetes mellitus $(p=0.02)$ and alcohol consumption $(p=0.04)$ were independently associated with hyponatremia.

Conclusion: High doses of furosemide and spironolactone, or concomitant use of these diuretics, seem to be an important cause of hyponatremia in HF patients, particularly in combination with advanced age, diabetes and alcohol consumption. Diuretic dose reduction may help avoid hyponatremia and improve clinical status and prognosis in such patients.
\end{abstract}

Keywords: Hyponatremia, Heart failure, Diuretics, Furosemide, Spironolactone

\section{Background}

Hyponatremia (a low serum sodium level) is the most common electrolyte disorder observed in hospitalized patients [1-3], with increased prevalence in the elderly $[4,5]$. At the same time, hyponatremia has been established as an important marker of disease severity and prognosis $[1,2,6]$. Several clinical conditions and cardiovascular risk factors, such as diabetes mellitus $[7,8]$,

\footnotetext{
* Correspondence: viktor.culic@st.t-com.hr

${ }^{2}$ Department of Cardiology, University Hospital Center Split, Šoltanska 1,

21000 Split, Croatia

${ }^{3}$ University of Split School of Medicine, Split, Croatia

Full list of author information is available at the end of the article
}

chronic kidney disease [9], chronic obstructive pulmonary disease [10], cirrhosis [6] and alcohol consumption [11], may also be associated with hyponatremia.

Although multiple neurohormonal mechanisms are involved in its pathogenesis, hyponatremia can also be a consequence of drugs, most notably of diuretic therapy $[9,12,13]$. This therapy is prescribed to patients with chronic renal failure [14], arterial hypertension [14], cirrhosis [6], and especially to those with symptomatic heart failure (HF) [9]. Thiazides, loop diuretics, and potassium sparing diuretics induce water and salt excretion $[12,14,15]$ and may promote sodium loss through renal effects [16]. It has been suggested that some diuretic

C C The Author(s). 2020 Open Access This article is licensed under a Creative Commons Attribution 4.0 International License, which permits use, sharing, adaptation, distribution and reproduction in any medium or format, as long as you give appropriate credit to the original author(s) and the source, provide a link to the Creative Commons licence, and indicate if changes were made. The images or other third party material in this article are included in the article's Creative Commons licence, unless indicated otherwise in a credit line to the material. If material is not included in the article's Creative Commons licence and your intended use is not permitted by statutory regulation or exceeds the permitted use, you will need to obtain permission directly from the copyright holder. To view a copy of this licence, visit http://creativecommons.org/licenses/by/4.0/ The Creative Commons Public Domain Dedication waiver (http://creativecommons.org/publicdomain/zero/1.0/) applies to the data made available in this article, unless otherwise stated in a credit line to the data. 
combinations may additionally increase the risk of hyponatremia $[17,18]$.

The aim of the present study was to explore the associations of cardiovascular drug use, particularly three most commonly used diuretics in Croatia, i.e. furosemide, hydrochlorothiazide and spironolactone, with hyponatremia in patients with HF. We additionally aimed to assess the possible role of diuretic drug doses and drug coadministration in the occurrence of hyponatremia in this clinical setting.

\section{Methods}

We performed an observational prospective cohort study at the Department of Cardiology and Department of Internal Medicine of the University Hospital Center Split, between February 1, 2015 and September 1, 2017. The study population included patients hospitalized because of HF (first manifestation or exacerbation of an existing disease). The inclusion criteria were: 1 ) clinical presentation typical for HF; 2) left ventricular ejection fraction (LVEF) $\leq 45 \%$ assessed by the Simpson method and/or diastolic dysfunction determined by echocardiography and 3) unchanged medications, including diuretic doses, for at least 1 month prior to hospital admission. Patients were excluded from the study if they had any acute or chronic disease other than elements of cardiorenal syndrome, that could disturb serum sodium levels (i.e., acute or chronic infections, endocrine and metabolic disorders, autoimmune, malignant, obstructive pulmonary or primary liver diseases).

For each patient, a structured questionnaire was filled out by specially trained interns or medical students, containing questions on general data, presence of previous cardiovascular diseases, cardiovascular risk factors and prehospital drug use. Because we were particularly interested in the effect of dose of the three most commonly used diuretics in Croatia, we collected data on the exact dose of furosemide (between 20 and $500 \mathrm{mg}$ ), hydrochlorothiazide (12.5 or $25 \mathrm{mg}$ ) and spironolactone $(25,50$ or $100 \mathrm{mg}$ ). A small number of patients with loop diuretic torasemide $(n=5)$ and potassium sparing diuretic eplerenone $(n=14)$ were excluded from the analysis. In Croatia, triamterene and amiloride are only exceptionally used and we had no patients who used these drugs. Other cardiovascular drugs were included in the analyses as dichotomous variables.

Basic heart rhythm was determined by electrocardiogram at admission. Blood samples were taken within the first hour of hospitalization. Initial electrolyte levels were determined as a part of the normal diagnostic evaluation. Hyponatremia was defined as serum sodium level $<136 \mathrm{mmol} / \mathrm{L}$. Elevated blood pressure $(\geq 130 / 85$ $\mathrm{mmHg}$ ) or use of antihypertensive medication were criteria for hypertension. Elevated nonfasting glucose $(\geq 11.1 \mathrm{mmol} / \mathrm{L}$ ) or previously established diabetes mellitus were criteria for diabetes diagnosis. Plasma concentration of N-terminal pro brain natriuretic peptide (NTproBNP), in $\mathrm{pmol} / \mathrm{L}$, was measured by using immunoassays (Roche Diagnostics GmbH, Mannheim, Germany). Kidney failure was defined as an estimated glomerular filtration rate (GFR) $<60 \mathrm{~mL} / \mathrm{min} / 1.73 \mathrm{~m}^{2}$, calculated using the 4-variable Modification of Diet in Renal Disease formula [19]. All patients underwent standard transthoracic echocardiographic examination at rest.

\section{Statistical analysis}

The data were expressed as percentages for dichotomous variables. Normally distributed continuous variables were presented as means with standard deviation. Variables with a skewed distribution were expressed as medians with interquartile ranges (IQR). Associations of clinical variables with hyponatremia were tested using $X^{2}$ test, $\chi^{2}$ goodness-of-fit test, Student $t$-test and MannWhitney- $U$ test, as appropriate. Correlations among continuous clinical variables were tested by linear regression analysis and expressed through the Pearson's correlation coefficient. In the multivariate analysis, a stepwise logistic regression was used to test the predictability of occurrence of hyponatremia in terms of baseline characteristics, LVEF, cardiovascular risk factors, and drug use, including diuretic doses in three different models. A multiple regression analysis (with calculation of the standardized correlation coefficient) was used to estimate the independent predictive association of baseline clinical characteristics, other markers of HF severity and cardiovascular drugs with serum NT-proBNP levels. A $p$ value of $<0.05$ was considered statistically significant. All statistical analyses were performed using IBM Statistical package for the social science (SPSS), software version 20.0 (SPSS Inc., Chicago, Illinois).

\section{Results}

Table 1 shows baseline characteristics of the 565 included patients. Average sodium level for all patients was $137.7 \pm 4.4 \mathrm{mmol} / \mathrm{L}(133.1 \pm 4.1 \mathrm{mmol} / \mathrm{L}$ for hyponatremic and $139.9 \pm 2.3 \mathrm{mmol} / \mathrm{L}$ for non-hyponatremic patients). There were $41.1 \%$ patients with LVEF $\leq 45 \%$ (Table 1). Out of these patients, 35.1\% had a mild dysfunction (LVEF 40-45\%), 38.8\% had moderate (LVEF $30-39 \%$ ), and $26.1 \%$ (LVEF < 30\%) had severe dysfunction. Compared to non-hyponatremic patients, hyponatremic patients were more often current smokers or alcohol consumers, more often had a LVEF $\leq 45 \%$, and less often had atrial fibrillation or flutter (Table 1). Hyponatremic patients on average had a higher urea and serum potassium, but lower serum chloride (Table 2).

Compared to patients who received no or only one diuretic, patients who received two or more diuretics were 
Table 1 Prehospital drugs and clinical characteristics of the study population and in study patients according to hyponatremia ( $N=565)$

\begin{tabular}{|c|c|c|c|c|}
\hline Clinical characteristics & All patients & Hyponatremic patients $(N=183)$ & Non-hyponatremic patients $(N=382)$ & $p$ \\
\hline Age (years \pm SD) & $73.1 \pm 10.6$ & $74.3 \pm 9.4$ & $72.9 \pm 10.5$ & 0.15 \\
\hline Male gender (\%) & 62.6 & 62.3 & 63.4 & 0.81 \\
\hline LVEF $\leq 45 \%(\%)$ & 41.1 & 48.1 & 37.7 & $0.02^{*}$ \\
\hline Previous AMI (\%) & 20.5 & 24.6 & 18.6 & 0.10 \\
\hline Arterial hypertension (\%) & 66.9 & 63.4 & 68.6 & 0.22 \\
\hline Diabetes mellitus (\%) & 33.8 & 38.8 & 34.4 & 0.08 \\
\hline Kidney failure (\%) & 28.2 & 31.7 & 26.4 & 0.19 \\
\hline Alcohol consumption (\%) & 30.3 & 33.3 & 23.8 & $0.01^{*}$ \\
\hline Current smokers (\%) & 14.5 & 20.2 & 11.8 & $0.01^{*}$ \\
\hline Atrial fibrillation/ flutter (\%) & 49.5 & 41.5 & 53.4 & $0.008^{*}$ \\
\hline \multicolumn{5}{|l|}{ Prehospital medication (\%) } \\
\hline Furosemide & 60.3 & 64.5 & 58.4 & 0.17 \\
\hline Hydrochlorothiazide & 16.5 & 14.8 & 17.2 & 0.45 \\
\hline Spironolactone & 17.9 & 24.6 & 14.7 & $0.004^{*}$ \\
\hline$\beta$-blocker & 55.4 & 51.9 & 57.1 & 0.25 \\
\hline Calcium antagonist & 20.5 & 19.1 & 21.2 & 0.14 \\
\hline ARB & 10.9 & 13.1 & 9.9 & 0.26 \\
\hline ACEI & 40.7 & 39.3 & 41.4 & 0.65 \\
\hline Aspirin & 31.1 & 27.9 & 32.7 & 0.24 \\
\hline Digoxin & 22.5 & 25.1 & 21.2 & 0.30 \\
\hline \multicolumn{5}{|l|}{ Coadministration of diuretics (\%) ${ }^{a}$} \\
\hline Furosemide + spironolactone & 16.5 & 23 & 13.1 & $0.003^{*}$ \\
\hline Furosemide + hydrochlorothiazide & 6.2 & 7.7 & 5.8 & 0.39 \\
\hline Furosemide + hydrochlorothiazide + spironolactone & 1.9 & 2.2 & 1.8 & 0.78 \\
\hline
\end{tabular}

Hyponatremia: serum sodium < $136 \mathrm{mmol} / \mathrm{L}$, LVEF: left ventricular ejection fraction, AMI: acute myocardial infarction, ARB Angiotensin II receptor I blocker, ACEI Angiotensin converting enzyme-inhibitor

$p$ values refer to the $t$-test or $x^{2}$ test as appropriate

*Statistically significant differences $(p<0.05)$

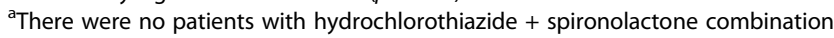

more often hyponatremic $\left(\chi^{2}=10.1 ; p=0.006\right)$. Hyponatremic patients received spironolactone more often, as well as the combination of furosemide with spironolactone (Table 1). We observed no significant association of concomitant use of furosemide, hydrochlorothiazide and spironolactone in combination with hyponatremia (Table 1 ) probably due to the small number of such patients $(n=11)$.

When considering drug dose, patients who received 50 or $100 \mathrm{mg}$ of spironolactone were significantly more often hyponatremic than those receiving $25 \mathrm{mg}$, as were those receiving $\geq 250 \mathrm{mg}$ of furosemide compared to those receiving lower doses (Fig. 1). Patients who received either 50 or $100 \mathrm{mg}$ of spironolactone almost always concomitantly used furosemide while those receiving $25 \mathrm{mg}$ more often used spironolactone only (Fig. S.1, Additional file 1). There was no significant association between dose of hydrochlorothiazide and hyponatremia (Fig. S.2, Additional file 1).
Patients who received calcium antagonists had a significantly higher LVEF compared to those who did not $(54 \%$ vs $46 \% ; p<0.001)$. Since the collection of plasma level of NT-proBNP was not included in the study protocol, this data was available for 148 of our patients. The levels of this marker of HF severity were significantly higher in hyponatremic $(n=41)$ than in nonhyponatremic $(n=107)$ patients; $969.1 \mathrm{pmol} / \mathrm{L}$ (median, IQR 307.6-2004.0) vs. 423.4 pmol/L (IQR 195.5-977.3); $p=0.006$. In the univariate analysis, NT-proBNP levels significantly correlated with the GFR, LVEF, and hydrochlorothiazide dose (Table S.1, Additional file 1).

\section{Multivariate analysis}

Because of the interrelation among drug doses in combination with diuretics and hyponatremia, we ran three separate multivariate models. When we included the use of each diuretic as a dichotomous variable (Table S.2, Additional file 1), we found no significant association 
Table 2 Laboratory findings of the study patients according to hyponatremia $(N=565)$

\begin{tabular}{|c|c|c|c|}
\hline Laboratory findings & Hyponatremic patients $(N=183)$ & Non-hyponatremic patients $(N=382)$ & $p$ \\
\hline Hemoglobin (median, IQR, g/L) & $127(112-144)$ & $132(116-144)$ & 0.57 \\
\hline Hematocrit (mean $\pm S D, L / L)$ & $0.39 \pm 0.07$ & $0.4 \pm 0.07$ & 0.11 \\
\hline Urea (median, IQR,mmol/L) & $10.5(7-15.5)$ & $8.7(6.3-12.2)$ & $0.004^{*}$ \\
\hline Serum creatinine (median, IQR, mg/dL) & $1.4(1.1-1.9)$ & $1.3(1-1.7)$ & 0.20 \\
\hline Serum potassium (mean $\pm \mathrm{SD}, \mathrm{mmol} / \mathrm{L}$ ) & $4.3 \pm 0.7$ & $4.1 \pm 0.6$ & $0.001^{*}$ \\
\hline Serum chloride (mean $\pm \mathrm{SD}, \mathrm{mmol} / \mathrm{L}$ ) & $97.2 \pm 5.5$ & $101.2 \pm 4.4$ & $<0.001^{*}$ \\
\hline Cardiac troponin I (median, IQR, ng/ml) & $0.051(0.020-0.108)$ & $0.039(0.018-0.089)$ & 0.12 \\
\hline Total cholesterol (median, IQR, mmol/L) & $3.4(3.1-4.9)$ & $4.3(3.5-5)$ & 0.57 \\
\hline HDL (median, IQR, mmol/L) & $1.3(0.9-1.8)$ & $1.3(1.3-1.8)$ & 0.71 \\
\hline LDL (median, IQR, mmol/L) & $2.4(1.9-3.2)$ & $2.5(1.9-3.1)$ & 0.92 \\
\hline Triglycerides (median, IQR, mmol/L) & $1.8(1.4-2.5)$ & $1.8(1.2-2.4)$ & 0.44 \\
\hline Total bilirubin (median, IQR, $\mu \mathrm{mol} / \mathrm{L}$ ) & $15.9(11.0-21.0)$ & $14.3(11.2-18.9)$ & 0.26 \\
\hline Direct bilirubin (median, IQR, $\mu \mathrm{mol} / \mathrm{L}$ ) & $4.0(2.4-7.0)$ & $4.0(2.8-6.0)$ & 0.68 \\
\hline Indirect bilirubin (median, IQR, $\mu \mathrm{mol} / \mathrm{L}$ ) & $11.0(8.6-13.9)$ & $10.2(8.1-13.1)$ & 0.08 \\
\hline Serum uric acid (median, IQR, $\mu \mathrm{mol} / \mathrm{L}$ ) & $476(381-574)$ & $440(367-545)$ & 0.10 \\
\hline AST (median, IQR, $\mu \mathrm{mol} / \mathrm{L}$ ) & $27.0(19.0-37.0)$ & $24.0(19.0-33.0)$ & 0.12 \\
\hline ALT (median, IQR, $\mu \mathrm{mol} / \mathrm{L}$ ) & $23.0(15.8-33.0)$ & $23.0(17.0-34.3)$ & 0.68 \\
\hline GGT (median, IQR, $\mu \mathrm{mol} / \mathrm{L}$ ) & $45.0(25.0-97.0)$ & $39.0(23.0-82.0)$ & 0.16 \\
\hline
\end{tabular}

Hyponatremia: serum sodium < $136 \mathrm{mmol} / \mathrm{L}, H D L$ High-density lipoprotein, LDL Low-density lipoprotein, AST Aspartate aminotransferase, ALT Alanine aminotransferase, GGT Gamma-glutamyl transferase

$p$ values refer to the Mann-Whitney $U$ test and $t$-test as appropriate

* Statistically significant differences $(p<0.05)$

with hyponatremia. In the second model, a combination of furosemide and spironolactone was an independent predictor of hyponatremia (Table S.3, Additional file 1). In the last model, we stratified the patients according to the results of the univariate analysis with cut-off doses for furosemide and spironolactone. We observed a significant independent association of both furosemide doses of $\geq 250 \mathrm{mg}$ and spironolactone doses $\geq 50 \mathrm{mg}$ with hyponatremia (Table 3). In all the three models, increasing age, diabetes mellitus and alcohol consumption were independent predictors of hyponatremia. Low GFR, low LVEF, cardiac troponin I levels and both spironolactone use and its dose were independent predictors of NTproBNP levels (Table S.4, Model 1 and 2, Additional file 1), after adjustment for baseline clinical characteristics, other markers of HF severity and cardiovascular drugs with possible impact on NT-proBNP levels.

\section{Discussion}

When accounting for demographic and clinical variables, the doses of $\geq 250 \mathrm{mg}$ of furosemide and $\geq 50 \mathrm{mg}$ of spironolactone received for at least a month, or concomitant use of both diuretics regardless of their dose, were independent predictors of hyponatremia at hospital admission of patients due to HF. In addition, increasing age, diabetes mellitus and alcohol consumption were baseline characteristics independently associated with the occurrence of hyponatremia.

Hyponatremia is a predictor of adverse outcomes, in both short- and long-term prognosis [9, 10, 20-26], and has been closely associated with increased length of inhospital stay [23, 24], rate of rehospitalizations, major complications [25], and risk for in-hospital mortality [24-26]. In addition, hyponatremia has been suggested as an important predictor of adverse in-hospital outcomes in all HF patients, regardless of the LVEF [27]. Our univariate analysis showed that hyponatremic patients more often had LVEF $\leq 45 \%$, but this association disappeared in the multivariate analysis. In HF, hyponatremia is a product of several simultaneous pathophysiological mechanisms, including arterial underfilling, activation of the sympathetic nervous system and reninangiotensin-aldosterone system, enhanced arginine vasopressin secretion, renal impairment and diuretic therapy $[2,6]$. Our study suggests that the net-effect of these mechanisms is more important for the occurrence of hyponatremia than isolated effect of LVEF. An inverse association of LVEF and GFR with NT-proBNP levels in our patients is compatible to the basic mechanisms of failing heart within the pathophysiological framework of the cardiorenal syndrome [28].

In addition to some smaller studies [29-31], a large cohort study using data from the Rotterdam study [12] 

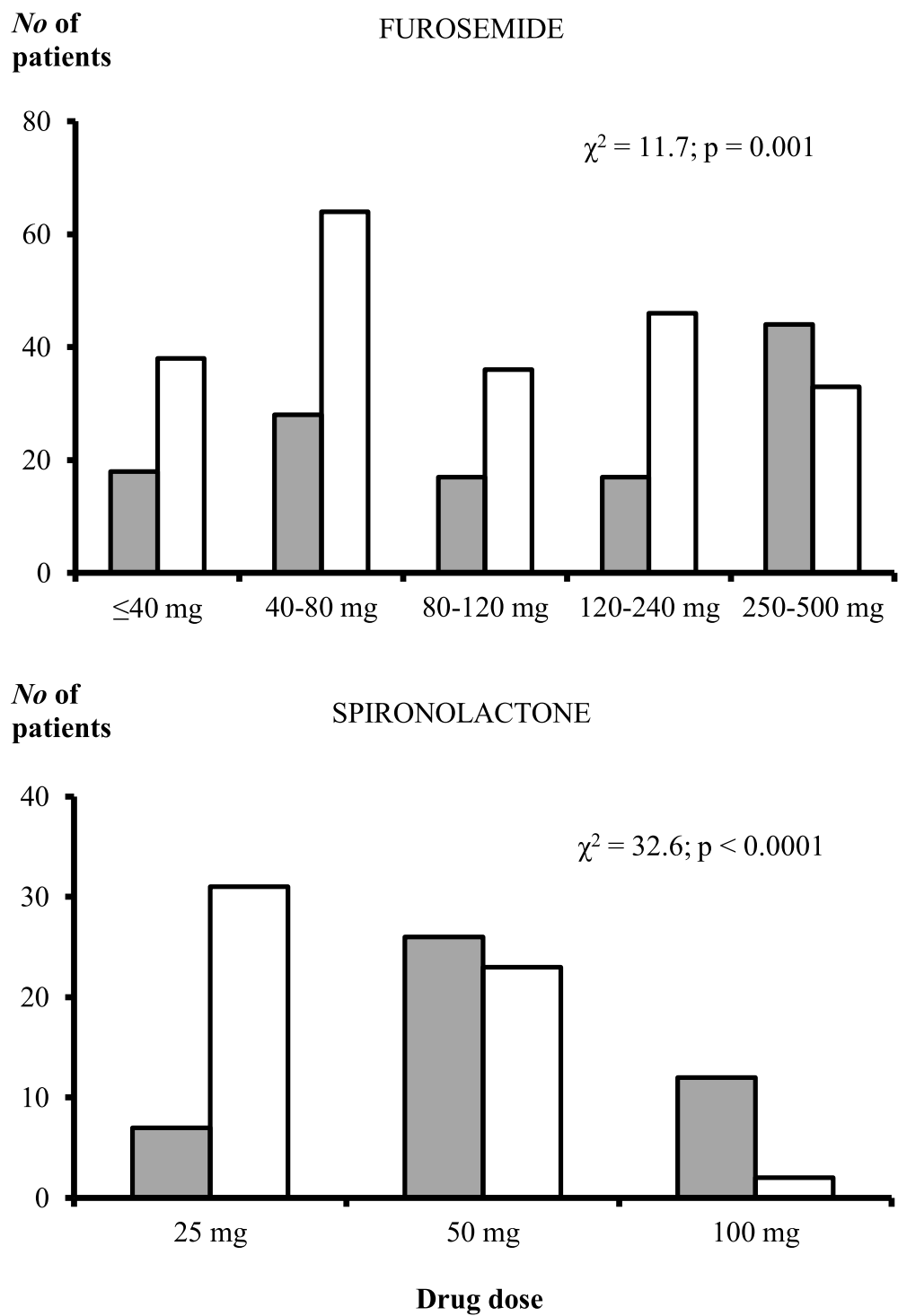

Fig. 1 Distribution of study patients according to furosemide and spironolactone dose and hyponatremia

and a retrospective study by Arampatzis et al. [14] have reported the association of thiazide use with hyponatremia. In contrast, we did not confirm such an association, regardless of the hydrochlorothiazide dose. However, none of our HF patients took $>25 \mathrm{mg}$ of hydrochlorothiazide. Most recently, the dose of $\geq 25 \mathrm{mg}$ of hydrochlorothiazide, in addition to advanced age, female sex, use of benzodiazepines or statins and previous cerebrovascular accident, has been suggested as a clinical predictor of hyponatremia among hypertensive patients taking thiazide diuretics [32]. There is a possibility that metabolic and other effects of thiazide diuretics may vary in specific populations which should be accounted for in future studies.

Several studies have linked the use of loop diuretics to hyponatremia [15, 33]. Loop diuretics promote natriuresis and water loss through the inhibition of sodium chloride reabsorption at the ascending limb of Henle's loop [17]. However, these drugs act at the macula densa, affecting both renal concentrating and diluting mechanisms [17], and when water loss is insufficiently replaced, hypernatremia may also occur [12, 33]. In contrast to some exceptions [9], our finding of $60 \%$ of HF patients taking furosemide is in agreement with 
Table 3 Multivariate analysis of the predicting association of clinical factors with occurrence of hyponatremia

\begin{tabular}{|c|c|c|}
\hline & OR $(95 \% C l)$ & $p$ \\
\hline Age (per 10-year increase) & $1.115(1.023-1.159)$ & $0.03^{*}$ \\
\hline Alcohol consumption & $1.112(1.002-1.273)$ & $0.04^{*}$ \\
\hline Male sex & $0.947(0.861-1.047)$ & 0.29 \\
\hline Kidney failure & $1.043(0.945-1.154)$ & 0.39 \\
\hline LVEF $\leq 45 \%$ & $0.943(0.994-1.001)$ & 0.25 \\
\hline Arterial hypertension & $0.947(0.854-1.049)$ & 0.29 \\
\hline Diabetes mellitus & $1.114(1.012-1.224)$ & $0.02^{*}$ \\
\hline Previous AMI & $1.053(0.946-1.191)$ & 0.31 \\
\hline Current smoking & $1.069(0.953-1.258)$ & 0.19 \\
\hline Hydrochlorothiazide & $0.976(0.863-1.093)$ & 0.63 \\
\hline 250 to $500 \mathrm{mg}$ furosemide & $1.138(1.043-1.344)$ & $0.009^{*}$ \\
\hline 50 to $100 \mathrm{mg}$ spironolactone & $1.197(1.126-1.484)$ & $0.0003^{*}$ \\
\hline$\beta$-blocker & $0.959(0.878-1.053)$ & 0.39 \\
\hline Calcium antagonist & $0.935(0.827-1.036)$ & 0.18 \\
\hline ARB & 1.049 (0.929-1.249) & 0.32 \\
\hline ACEI & $1.074(0.973-1.178)$ & 0.16 \\
\hline Aspirin & $0.977(0.886-1.076)$ & 0.63 \\
\hline Digoxin & $0.943(0.837-1.045)$ & 0.24 \\
\hline
\end{tabular}

Odds ratios $(O R)$ and $p$ values were obtained from the logistic regression analysis. Cl Confidence Interval, LVEF Left ventricular ejection fraction, $A M I$ Acute myocardial infarction, $A R B$ Angiotensin II receptor I blocker, ACEI Angiotensin converting enzyme-inhibitor

* Statistically significant differences $(p<0.05)$

other studies on this topic [15, 34]. We found a strong association of high doses, i.e., 250 to $500 \mathrm{mg}$ of furosemide with hyponatremia, in both univariate and multivariate analysis. In the previous studies, loop diuretics were analyzed as the class, and dosage was not taken into account $[9,12,14,15,33]$. This may at least partly explain conflicting results in the association between loop diuretic use and serum sodium levels, including hyponatremia $[15,33]$, hypernatremia $[12,33]$ or lack of association $[9,14]$.

A recent study in stable HF patients, in whom the furosemide dose was reduced by $50 \%$, has shown that this change may cause a $20 \%$ increase in GFR among those with GFR lower than $60 \mathrm{ml} / \mathrm{min} / 1.73 \mathrm{~m}^{2}$ [35]. We observed no association of kidney failure with hyponatremia in either univariate or multivariate analysis. This suggests that other significant predictors such as diuretics, increasing age, diabetes mellitus or alcohol consumption play a more important role in the occurrence of hyponatremia. Lowering GFR may be an adverse effect of higher diuretic doses which occasionally may worsen kidney failure.

In this line, a reduction of furosemide dose of $\geq 120 \mathrm{mg}$ to a third of the baseline dose in patients with HF, has been associated with increased 1- and 2-year survival rates free of hospitalization or cardiac death [36]. Our results extend this knowledge by strongly linking the dose of $\geq 250 \mathrm{mg}$ to hyponatremia. Therefore, a careful titration and reduction of furosemide dose below $250 \mathrm{mg}$ seems to be an important clinical goal, whenever possible.

Spironolactone, a potassium sparing diuretic, has also been implicated in the development of hyponatremia $[10,12]$. A possibility that coadministration of a second diuretic with potassium sparing diuretic can either cause or aggravate hyponatremia has been reported $[17,18]$. A fact that every fourth of our patients concomitantly used spironolactone with furosemide, and nearly all of those who took $\geq 50 \mathrm{mg}$ of spironolactone, supports this possibility. When drug doses were taken into account, we observed an independent association of high spironolactone dose (50 or $100 \mathrm{mg}$ daily) with hyponatremia. By inhibiting aldosterone-induced synthesis of epithelial $\mathrm{Na}^{+}$channels and consequently, $\mathrm{Na}^{+}-\mathrm{K}^{+}$exchange, spironolactone enhances natriuresis [17]. Our results suggest that dose of $25 \mathrm{mg}$ of spironolactone is relatively safe, while doses of 50 or $100 \mathrm{mg}$, or concomitant use with furosemide, probably enhance natriuresis to the extent that often cause hyponatremia. As in the case of furosemide, this suggests that a reduction of the spironolactone dose may be a useful clinical approach. The strong positive association between NT-pro BNP levels and spironolactone use, as well as its dose, could be a consequence of more frequent spironolactone prescription in higher dose to patients with most severe clinical HF. Interestingly, the dose of furosemide did not correlate with NT-pro BNP levels. It may be assumed that introduction of spironolactone and increase in its dose is most often gradual and compatible with the severity of HF. In contrast, variations in the dose of furosemide could be more frequent and more subjected to other clinical symptoms associated with electrolyte disbalance, changes in volume status and other pathophysiological consequences of cardiorenal syndrome.

Hyponatremia commonly occurs in elderly patients [4-6] which is supported by our results. The underlying pathophysiological mechanisms include age-related impairment in water excretory capacity causing a reduction in GFR [4], concomitant use of diuretics and central nervous system active drugs $[4,5]$, the syndrome of inappropriate antidiuretic hormone secretion [37] and the presence of other comorbidities such as HF [1, 2], diabetes mellitus [7, 8], kidney failure [9], cirrhosis [6] and others [6]. Alcohol consumption was also independently associated with hyponatremia. Patients with a chronic alcohol-use disorder commonly exhibit hyponatremia, as a result of increased vasopressin levels which induce an increased urine osmolality and decreased clearance of free water [11]. 
Diabetic patients frequently develop a wide array of electrolyte and acid-base disorders [7, 8]. Patients with diabetes mellitus are usually hyponatremic [8], a finding which is concurred by our results. In the hyperglycemic state, hyponatremia develops as a result of transition of water out of the cells and a reduction in sodium levels through dilution [7]. On the other hand, increased or normal serum sodium levels in diabetic patients may be associated with a significant deficit in total body water [8]. Other important causes and types of sodium disorders in patients with diabetes include osmotic diuresis induced hypovolemic hyponatremia [38], drug induced hyponatremia (oral hypoglycemics, insulin, tricyclic antidepressants) [39], pseudohyponatremia induced by hypertriglyceridemia [40] and pseudohypernatremia due to severe hypoproteinemia [7].

Cardiac troponin is another biomarker with an important prognostic value in acute HF, which has been consistently shown to correlate with increased morbidity and mortality [41]. A positive association between NTproBNP and troponin I levels observed in our patients confirms its role as a valuable clinical indicator of HF severity. Calcium antagonist therapy is not recommended in patients with HF and reduced LVEF [42]. Our patients who received calcium antagonists had a significantly higher and on average preserved LVEF which indicates that these medications are predominantly prescribed according to current recommendations.

\section{Study limitations}

There are several limitations to our study. Firstly, in addition to serum sodium level, volemic status is a closely interrelated factor which determines the course and prognosis of HF patients. Both factors are significantly dependent on the effects of diuretic therapy. However, we did not have an insight into the patients' volume status, but evaluation of congestion and clinical euvolaemia remains challenging since no reliable clinical test exists to determine euvolaemia [43]. Secondly, we did not collect data on several medications which may also influence serum sodium level, such as benzodiazepines, antiepileptics, selective serotonin reuptake inhibitors and non-steroidal anti-inflammatory drugs [38]. Thirdly, we did not collect data on the New York Heart Association class, previous HF hospitalizations, duration or worsening of HF symptoms, and mechanisms of death in our patients. Finally, we investigated only patients with HF, and there is a possibility that our findings may not be generalized to other patient subgroups.

\section{Conclusions}

The pathogenesis of hyponatremia is multifactorial. Among patients hospitalized because of HF, doses of $\geq 250 \mathrm{mg}$ of furosemide and $\geq 50 \mathrm{mg}$ of spironolactone received for at least a month, or concomitant use of both diuretics regardless of their dose, were independently associated with hyponatremia at admission. Future research should explore whether a targeted reduction of dose of furosemide and spironolactone in clinically stable HF patients, particularly if they are elderly, diabetics or alcohol consumers, is safe and tolerable and whether this may help avoid hyponatremia and improve their clinical status and prognosis.

\section{Supplementary information}

Supplementary information accompanies this paper at https://doi.org/10. 1186/s40360-020-00431-4

Additional file 1: Fig. S.1. Patients taking spironolactone according to dose and coadministration with furosemide. Fig. S.2. Distribution of study patients according to hydrochlorothiazide dose and hyponatremia.

Table S.1. Univariate correlations of clinical variables with serum NTproBNP levels. Table S.2 (Model 1). Multivariate analysis of the predicting association of clinical factors with occurrence of hyponatremia. Table S.3 (Model 2). Multivariate analysis of the predicting association of clinical factors with occurrence of hyponatremia. Table S.4 (Model 1, Model 2). Multivariate analysis of the predicting association of clinical factors with serum NT-proBNP levels.

\section{Abbreviations}

HF: Heart failure; LVEF: Left ventricular ejection fraction; NT-proBNP: Nterminal pro brain natriuretic peptide; GFR: Glomerular filtration rate; IQR: Interquartile range; SPSS: Statistical package for the social science

\section{Acknowledgements}

We are grateful for the assistance of Mary Louise Stover in the preparation of the manuscript.

\section{Authors' contributions}

IV participated in the data collection, data analysis and interpretation, drafting, critical revision and approval of the article. ŽB participated in the data collection, data analysis and interpretation, drafting and approval of the article. MJP participated in the data collection. VČ contributed to the concept and design, data analysis and interpretation, drafting, critical revision and approval of the article. The author(s) read and approved the final manuscript.

Funding

No funding was received in the preparation of this article.

\section{Availability of data and materials}

The datasets analyzed during the current study are available from the corresponding author on reasonable request.

\section{Ethics approval and consent to participate}

The study protocol was approved by the Ethics Committee of the University Hospital Center Split (Number 2181-147-01/06/M.B.-16-2) and all patients gave their written informed consent for participation.

Consent for publication

Not applicable.

\section{Competing interests}

The authors declare they have no competing interests.

\section{Author details}

${ }^{1}$ University Hospital Center Split, Split, Croatia. ${ }^{2}$ Department of Cardiology, University Hospital Center Split, Šoltanska 1, 21000 Split, Croatia. ${ }^{3}$ University of Split School of Medicine, Split, Croatia. 
Received: 1 April 2020 Accepted: 16 July 2020

Published online: 03 August 2020

\section{References}

1. Filippatos TD, Elisaf MS. Hyponatremia in patients with heart failure. World J Cardiol. 2013;5(9):317-28.

2. Urso C, Brucculeri S, Caimi G. Acid-base and electrolyte abnormalities in heart failure: pathophysiology and implications. Heart Fail Rev. 2015;20(4): 493-503.

3. Milionis HJ, Alexandrides GE, Liberopoulos EN, Bairaktari ET, Goudevenos J, Elisaf MS. Hypomagnesemia and concurrent acid-base and electrolyte abnormalities in patients with congestive heart failure. Eur J Heart Fail. 2002; 4(2):167-73.

4. Filippatos TD, Makri A, Elisaf MS, Liamis G. Hyponatremia in the elderly: challenges and solutions. Clin Interv Aging. 2017;12:1957-65.

5. Woodward M, Gonski P, Grossmann M, Obeid J, Scholes R, Topliss DJ. Diagnosis and management of hyponatraemia in the older patient. Intern Med J. 2018:48(Suppl):5-12.

6. Schrier RW, Sharma S, Shchekochikhin D. Hyponatraemia: more than just a marker of disease severity? Nat Rev Nephrol. 2013:9(1):37-50.

7. Liamis G, Liberopoulos E, Barkas F, Elisaf M. Diabetes mellitus and electrolyte disorders. World J Clin Cases. 2014;2(10):488-96.

8. Palmer BF, Clegg DJ. Electrolyte and Acid-Base disturbances in patients with diabetes mellitus. N Engl J Med. 2015;373(6):548-59.

9. Ali K, Workicho A, Gudina EK. Hyponatremia in patients hospitalized with heart failure: a condition often overlooked in low-income settings. Int J Gen Med. 2016;9:267-73.

10. Bavishi C, Ather S, Bambhroliya A, Jneid H, Virani SS, Bozkurt B, et al. Prognostic significance of hyponatremia among ambulatory patients with heart failure and preserved and reduced ejection fractions. Am J Cardiol. 2014;113(11):1834-8.

11. Palmer BF, Clegg DJ. Electrolyte disturbances in patients with chronic alcohol-use disorder. N Engl J Med. 2017;377(14):1368-77.

12. Liamis G, Rodenburg EM, Hofman A, Zietse R, Stricker BH, Hoorn EJ. Electrolyte disorders in community subjects: prevalence and risk factors. Am J Med. 2013;126(3):256-63.

13. Liamis $\mathrm{G}$, Milionis $\mathrm{H}$, Elisaf M. A review of drug-induced hyponatremia. Am J Kidney Dis. 2008;52(1):144-53.

14. Arampatzis S, Funk GC, Leichtle AB, Fiedler GM, Schwarz C, Zimmermann H, et al. Impact of diuretic therapy-associated electrolyte disorders present on admission to the emergency department: a cross-sectional analysis. BMC Med. 2013;11:83.

15. Nankabirwa $H$, Kalyesubula R, Ssinabulya I, Katabira ET, Cumming RG. A cross-sectional study of hyponatraemia among elderly patients with heart failure in Uganda. BMJ Open. 2016;6(5):e009775.

16. Oren RM. Hyponatremia in congestive heart failure. Am J Cardiol. 2005; 95(9A):2B-7B.

17. Tamargo J, Segura J, Ruilope LM. Diuretics in the treatment of hypertension. Part 2: loop diuretics and potassium-sparing agents. Expert Opin Pharmacother. 2014;15(5):605-21.

18. Fidler HM, Goldman J, Bielawska CA, Rai GS, Hoffbrand BI. A study of plasma sodium levels in elderly people taking amiloride or triamterene in combination with hydrochlorothiazide. Postgrad Med J. 1993;69(816):797-9.

19. Levey AS, Bosch JP, Lewis JB, Greene T, Rogers N, Roth D. A more accurate method to estimate glomerular filtration rate from serum creatinine: a new prediction equation. Modification of diet in renal disease study group. Ann Intern Med. 1999;130(6):461-70.

20. Costache II, Alexandrescu DM, Cimpoeşu D, Petriş OR, Petriş AO. Hyponatremia--risk factor in patients with chronic heart failure--clinical, evolutive and therapeutic implications. Rev Med Chir Soc Med Nat lasi. 2014;118(2):315-9.

21. Gross P, Palm C. Thiazides: do they kill? Nephrol Dial Transplant. 2005;20(11): 2299-301.

22. Reynolds RM, Seckl JR. Hyponatraemia for the clinical endocrinologist. Clin Endocrinol. 2005;63(4):366-74.

23. Gheorghiade M, Abraham WT, Albert NM, Gattis Stough W, Greenberg BH, O'Connor CM, et al. Relationship between admission serum sodium concentration and clinical outcomes in patients hospitalized for heart failure: an analysis from the OPTIMIZE-HF registry. Eur Heart J. 2007;28(8): 980-8.
24. Lee DS, Austin PC, Rouleau JL, Liu PP, Naimark D, Tu JV. Predicting mortality among patients hospitalized for heart failure: derivation and validation of a clinical model. JAMA. 2003;290(19):2581-7.

25. Rich MW, Beckham V, Wittenberg C, Leven CL, Freedland KE, Carney RM. A multidisciplinary intervention to prevent the readmission of elderly patients with congestive heart failure. N Engl J Med. 1995;333(18):1190-5.

26. Wong PS, Davidsson GK, Timeyin J, Warren A, Watson DJ, Vincent R, et al. Heart failure in patients admitted to hospital: mortality is still high. Eur J Intern Med. 2002:13(5):304-10.

27. Park JJ, Cho YJ, Oh IY, Park HA, Lee HY, Kim KH, et al. Short and long-term prognostic value of hyponatremia in heart failure with preserved ejection fraction versus reduced ejection fraction. An analysis of the Korean acute heart failure registry. Int J Cardiol. 2017;248:239-45.

28. Yogasundaram H, Chappell MC, Braam B, Oudit GY. Cardiorenal syndrome and heart failure-challenges and opportunities. Can J Cardiol. 2019:35(9): 1208-19.

29. Chow KM, Szeto CC, Wong TY, Leung CB, Li PK. Risk factors for thiazideinduced hyponatraemia. QJM. 2003;96(12):911-7.

30. Chow KM, Kwan BC, Szeto CC. Clinical studies of thiazide-induced hyponatremia. J Natl Med Assoc. 2004;96(10):1305-8.

31. Cohen DL, Townsend RR. Hyponatremia and thiazides. J Clin Hypertens. 2012;14(9):653.

32. Kanchanasurakit S, Saokaew S, Siriplabpla W, Arsu A, Boonmak W, Watcharasiriphong W. Development of a hyponatremia screening tool (ABCDF-S score) for patients with hypertension using thiazide diuretic agents. J Clin Pharm Ther. 2020. https://doi.org/10.1111/jcpt.13123 [Epub ahead of print].

33. Deubner N, Berliner D, Frey A, Güder G, Brenner S, Fenske W, et al. Dysnatraemia in heart failure. Eur J Heart Fail. 2012;14(10):1147-54.

34. Damman K, Kjekshus J, Wikstrand J, Cleland JG, Komajda M, Wedel H, et al. Loop diuretics, renal function and clinical outcome in patients with heart failure and reduced ejection fraction. Eur J Heart Fail. 2016;18(3):328-36.

35. McKie PM, Schirger JA, Benike SL, Harstad LK, Chen HH. The effects of dose reduction of furosemide on glomerular filtration rate in stable systolic heart failure. JACC Heart Fail. 2014;2(6):675-7.

36. Kapelios CJ, Kaldara E, Ntalianis A, Nana E, Pantsios C, Repasos E, et al. Lowering furosemide dose in stable chronic heart failure patients with reduced ejection fraction is not accompanied by decompensation: a randomized study. Int J Cardiol. 2014;177(2):690-2.

37. Shapiro DS, Sonnenblick M, Galperin I, Melkonyan L, Munter G. Severe hyponatraemia in elderly hospitalized patients: prevalence, aetiology and outcome. Intern Med J. 2010;40(8):574-80.

38. Chiasson JL, Aris-Jilwan N, Bélanger R, Bertrand S, Beauregard H, Ekoé JM, et al. Diagnosis and treatment of diabetic ketoacidosis and the hyperglycemic hyperosmolar state. CMAJ. 2003;168(7):859-66.

39. Palmer BF, Gates JR, Lader M. Causes and management of hyponatremia. Ann Pharmacother. 2003;37(11):1694-702.

40. Liamis G, Liberopoulos E, Barkas F, Elisaf M. Spurious electrolyte disorders: a diagnostic challenge for clinicians. Am J Nephrol. 2013;38(1):50-7.

41. Wettersten N, Maisel A. Role of cardiac troponin levels in acute heart failure. Card Fail Rev. 2015;1(2):102-6.

42. Yancy CW, Jessup M, Bozkurt B, Butler J, Casey DE, Drazner MH, et al. ACCF/ AHA guideline for the Management of Heart Failure. Circulation. 2013;2013, 128(16).

43. Mullens W, Damman K, Harjola VP, Mebazaa A, Brunner-La Rocca HP, Martens $P$, et al. The use of diuretics in heart failure with congestion - a position statement from the heart failure Association of the European Society of cardiology. Eur J Heart Fail. 2019;21(2):137-55.

\section{Publisher's Note}

Springer Nature remains neutral with regard to jurisdictional claims in published maps and institutional affiliations. 